\title{
Application of 3D Laser Scanning for Digitization, Design and Analysis of Multistoried Building
}

DOI : 10.36909/jer.13419

\author{
Abdul Qadir Bhatti ${ }^{*}{ }^{* * *}$, Abdul Wahab ${ }^{* *}$, Wadea Sindi* \\ * Department of Civil Engineering, Islamic University of Madinah, KSA \\ ** School of Civil Engineering, Universiti Teknologi Malaysia, 81310, Johor, Malaysia \\ *,**Corresponding author: draqbhatti@iu.edu.sa
}

\begin{abstract}
Laser scanning is a fast-developing technology, which collects millions of points and creates a framework within a few minutes, generating a 'point cloud' of the structure. Laser scanning is a quite new but rapidly evolving technology that has been reviewed. this research study has used most modern models of laser scanners and their accompanying software that are capable of accurate capture and alignment of point clouds. Consequently, the laser scans have precisely captured the current geometry of each structure, which is irregular in many cases due to inherently complex geometry, anomalies during the original construction, aging, deterioration, and structural damage. As both the exterior and interior of the structure have been scanned, the point cloud became a digital 3D image of the historical building, which can be virtually toured from inside and outside. A 4-story public building was scanned using a 3D laser scanner to determine the architectural and structural drawings of the response to an earthquake. The application of passive control using a damper with the laser scanner has been modelled in this study. The results corroborate that this technique provides the best outcomes for reducing seismic damage collapses.
\end{abstract}

Keywords: 3D Laser scanner, Passive Control System, Seismic Design, Finite Element Methods

\section{Introduction}

Nowadays 3D laser scanning is an innovative technique for acquiring the precise size and shape of an object as a three-dimensional image. This method gathers data including hidden shapes with complex geometry, and provides digitally improved quality and additional specifics of the scanned 3D objects. It generates a digital replica of real-world objects, according to the user's requirements, that can be altered and printed.

Generally, in the 21 st century, technologists are utilizing such innovation in a reverse fashion: 3D scans or drawings are used as input to CAD and 3D printing slicer programs, which are usually compatible with 3D scanner files. The process of getting together and combining the individual scans as a 3D scanning network were described. Bhatti et al. (2021) and Ebrahim (2015); 
The FARO Focus scanner calculates the as-built state of heritage sites, auditoriums, historical buildings, palaces, temples, art museums, and much more. Karan kamani (2020); reports that it is used in building documentation and topography.

Several other works have been reported by Shan et al. (2014); 3D scans were used in the restoration of ash-Shafei Mosque used 3D scans in the restoration of the most significant mosque surviving in Jeddah, in a project that was launched in 2011 under Al-Turath Foundation and Historic Jeddah Municipality and completed in 2016. Saudi Commission (2017). Furthermore, in separate research studies, used laser scanning for structural evaluations in studies related to storm and earthquake damage for structures in Uzbekistan, as well as California, USA. ICOMOS (2011) and Mosalam et al. (2014)

\section{Passive Control System}

In the present day, concrete is an extensively used material with the application of innovative techniques, as studied by Wahab et al. (2021); the structural design methodology for seismic response control is broadly accepted and applied in Civil Engineering. Recently, attention has been given to improvement of dampers and control techniques for structures like passive control systems, active control systems, and semi-active control systems, giving importance to enhanced seismic responses of bridges and buildings. A passive control system does not need a power supply, whereas active control systems need an external power supply. Serious efforts are underway to progress the structural control idea into practical expertise which is integrated with the structures. Bhatti AQ. (2013) and Heysami, A (2015)

Dampers are categorized by their performance as friction, mass dampers, viscoelastic, metal (flowing), viscous, and shape memory alloys (SMA). Figure 1 shows various dampers in use, such as friction dampers in retrofitting, PVD damper, and viscous damper. Among the advantages of using dampers is that they are easy to install and replace, and to coordinate with other structural members. Bhatti AQ. (2016)
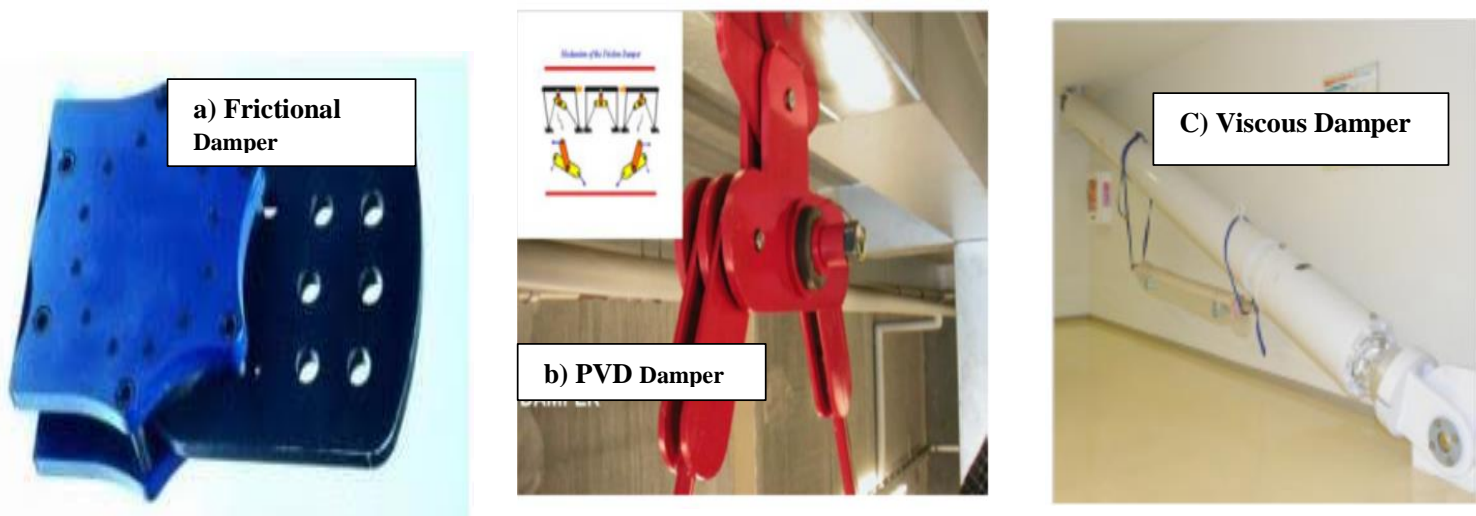

Figure 1: Illustrates the various dampers in use a) friction dampers in retrofitting, b) PVD damper, and c) Viscous damper

Typically, forces acting on the structure, like an earthquake, may cause unwanted vibration. The seismic waves generated by an earthquake will cause a building to sway and fluctuate in several ways, varying on the frequency and control of ground motion and the height 
of the building. In fact, the first specific damping mechanisms for earthquakes were not established until late in the 1950s. Nevertheless, high rise and leaning buildings may suffer natural frequency fluctuations under ambient temperatures, wind speed, and relative humidity changes, which means they need a tough design.

\section{Earthquake Hazard in Saudi Arabia}

Usually, in Saudi Arabia, the earthquake hazard is categorized as medium, shown in Figure 2 . This means a $10 \%$ probability of theoretically destructive shaking in the project area in the next 50 years. The earthquake's effects should be studied in all phases of the project. However, in Madinah, the earthquake hazard is classified as a low figure within the Saudi Arabia Earthquakes Regions; that is, a $2 \%$ chance of damaging shaking by earthquake.
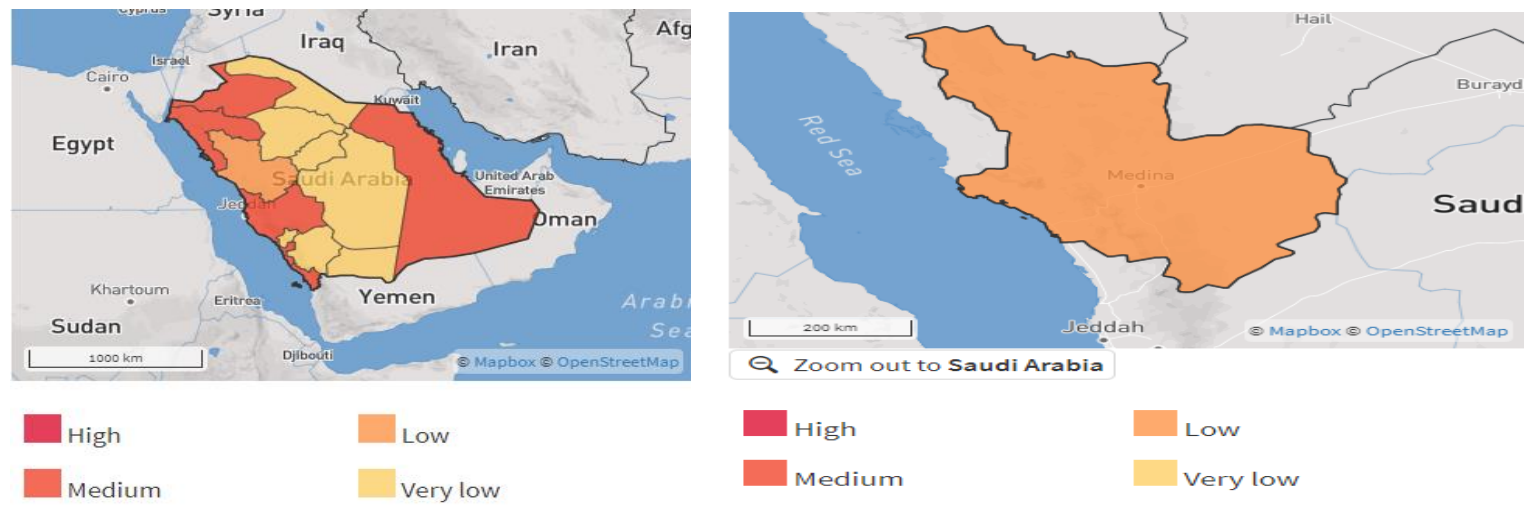

Figure 2: Illustrates the Saudi Arabia Earthquakes Regions

The city of Madinah suffered a 2.5 magnitude earthquake according to the Saudi Geological Society and there were no reports of damage from the earthquake in January 16, 2018. The earthquake epicenter was $14 \mathrm{~km}$ northwest of Madinah, at a depth of seven kms below the surface.

Every year, earthquakes worldwide cause thousands of deaths and a huge loss of property. There is a need to take adequate measures depending on the area's seismicity to minimize deaths and damage to the property. The purpose of this study is to find the best technique to reduce the seismic damage to a building through research using the responses of a scale model of the building to waves that are generated. Methods for reducing the damage by an earthquake are also analyzed and the Faro 3D 150-S laser scanner is used for scanning purposes to assess the building's data.

\section{Description of the Proposed Building for Laser Scanning}

Figure 3 displays the Faro 3D 150-S laser scanner equipment used in this study for assessing data. Figure 4 shows the building selected for assessing data in this study. Structural damage represents degradation of the building's structural support systems, like walls and frames. 
The structure is an engineering building located in the Islamic university. The building has four stories with a typical height of $24.39 \mathrm{~m}$, and a plan area of the building of $29.70 \times 29.70$ $\mathrm{m}^{2}$. The building has a reinforced concrete frame, precast hollow core unit lab system at different floor levels. It houses elevators, classrooms, labs and offices. The local seismic zone of the building is located in 2A, according to UBC 1997. The concrete design is based on ACI318-02 and all other relevant ACI codes, and live loads and wind loads are based on ASCE 702. From the available design data, the strength of the concrete is $32 \mathrm{MPa}$, and reinforcement is $420 \mathrm{MPa}$. Varum et al. (2013),
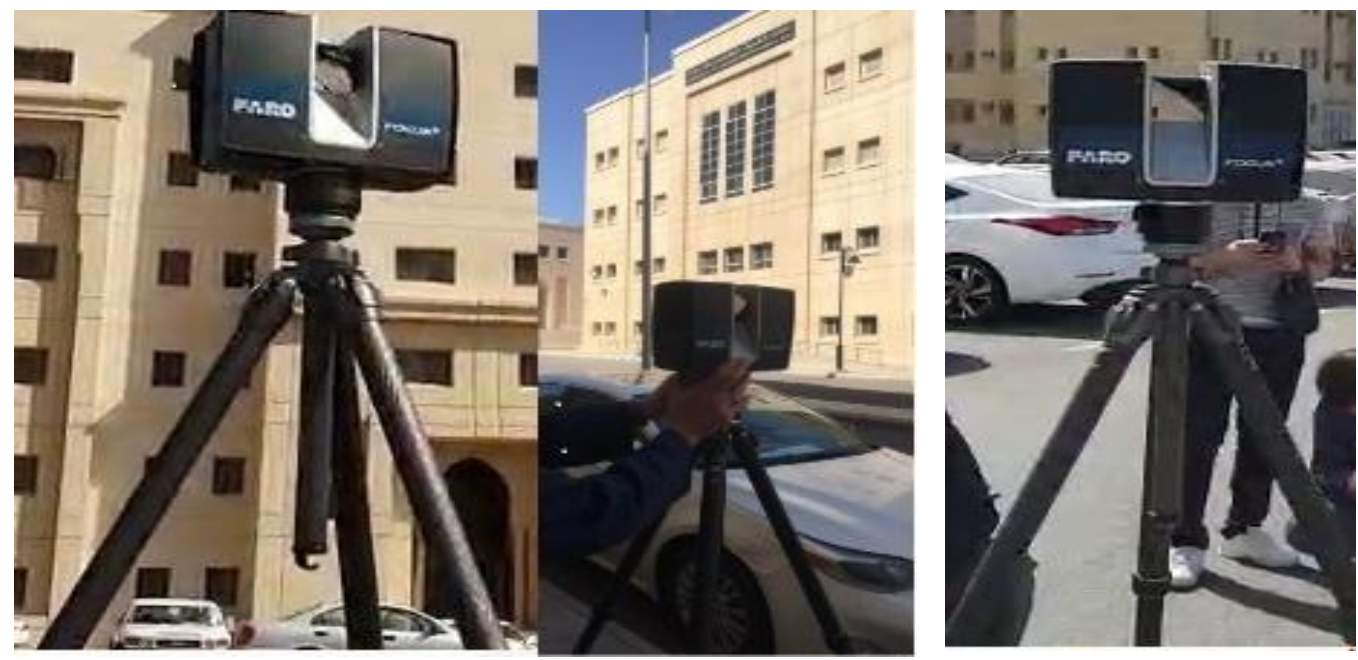

Figure 3: displays the Faro 3D 150-S laser scanner equipment used in this study for assessing data

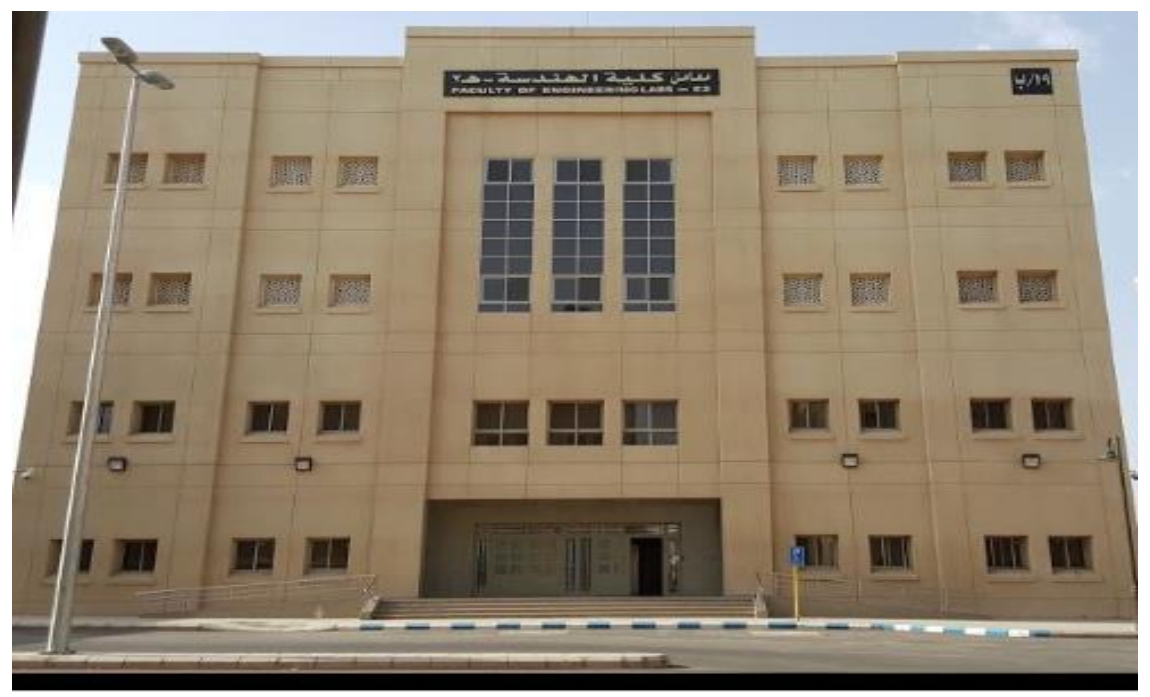

Figure 4: Demonstrates the building with front elevation selected for assessing data 


\section{Methodology for 3D laser scanner Setup}

To get started, initially set up the tripod, then mount the scanner onto the tripod. Insert the SD card and supply power to the scanner. Switch the scanner on and set the scanning parameters according to the scanning object. Then start the scan and wait until the scanner completes the scanning. Power off the scanner after completion of scanning. The Faro 3D 150$\mathrm{S}$ laser scanner is shown in Figure 5 (a). The checkerboards used for Faro 3D 150-S laser scanner to precisely scan the object and assess building data are illustrated in Figure 5 (b).

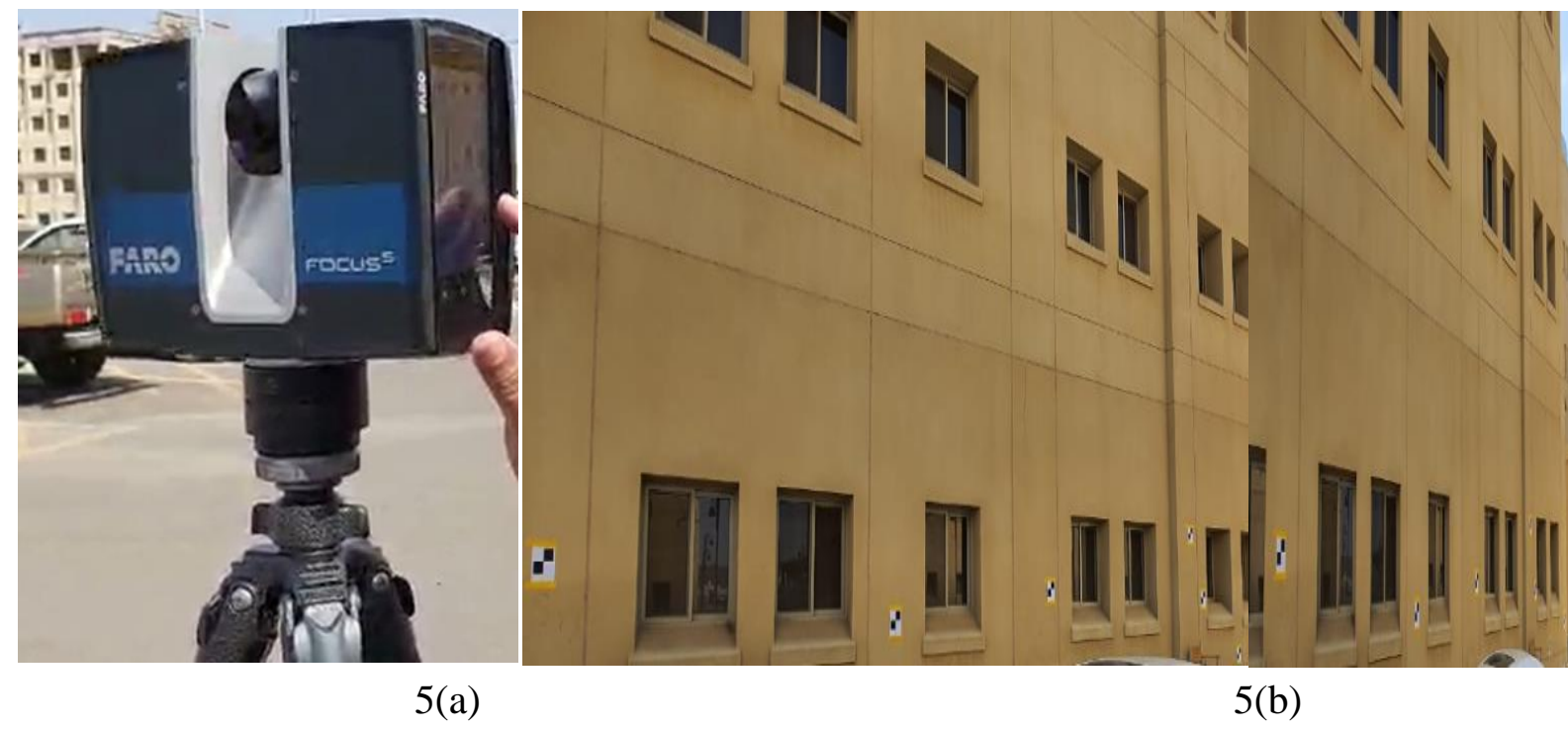

Figure 5 (a) shows the Faro 3D 150-S laser scanner and Figure 5 (b) shows the checkerboards used for Faro 3D 150-S laser scanner scanning purpose for assessing data of the building.

Figure 6 shows the point cloud dimensions generated by Autodesk ReCap Software, and in Figure 7, the point cloud dimensions developed by Faro Scene Software are shown. In various research studies, Wahab et al. (2019) and Bhatti (2016) carried out digitization and 3D laser scanning with finite element (FE) modeling for historical structures and monuments in Saudi Arabia. 


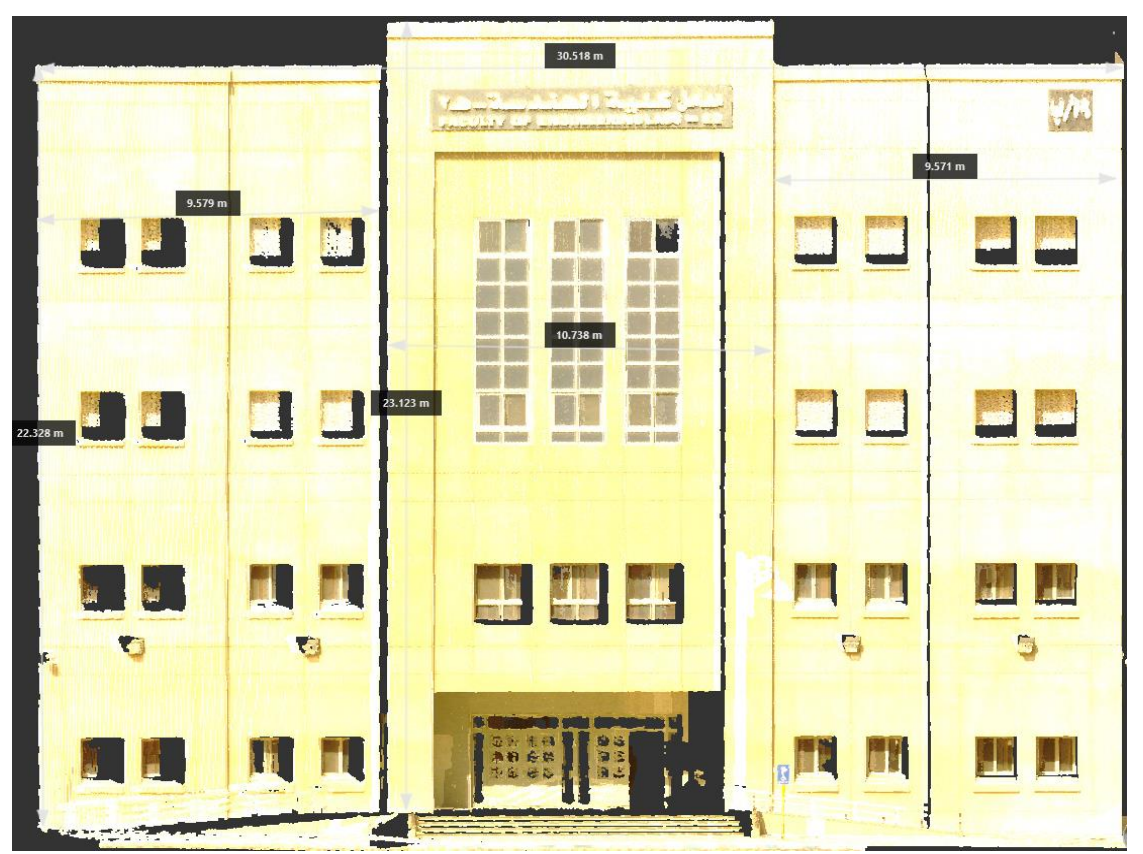

Figure 6: Shows the Point Cloud dimensions captured by Autodesk ReCap Software[*]

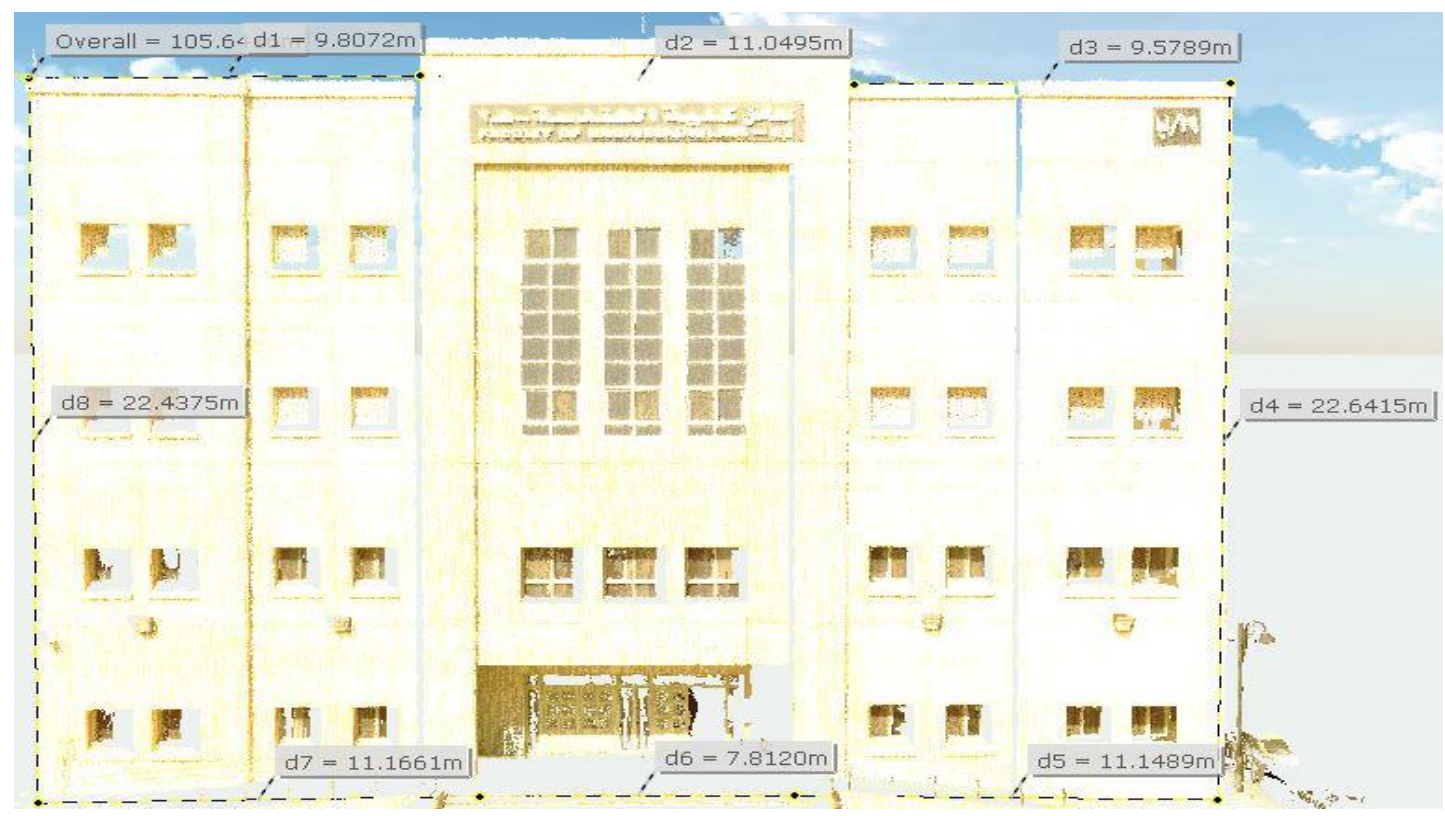

Figure 7: Illustrates the Point Cloud dimensions captured by Faro Scene Software [**]

The point clouds were then converted into architectural and structural drawings of the subjected building, as shown in the following figures 8, 9 and 10 . 


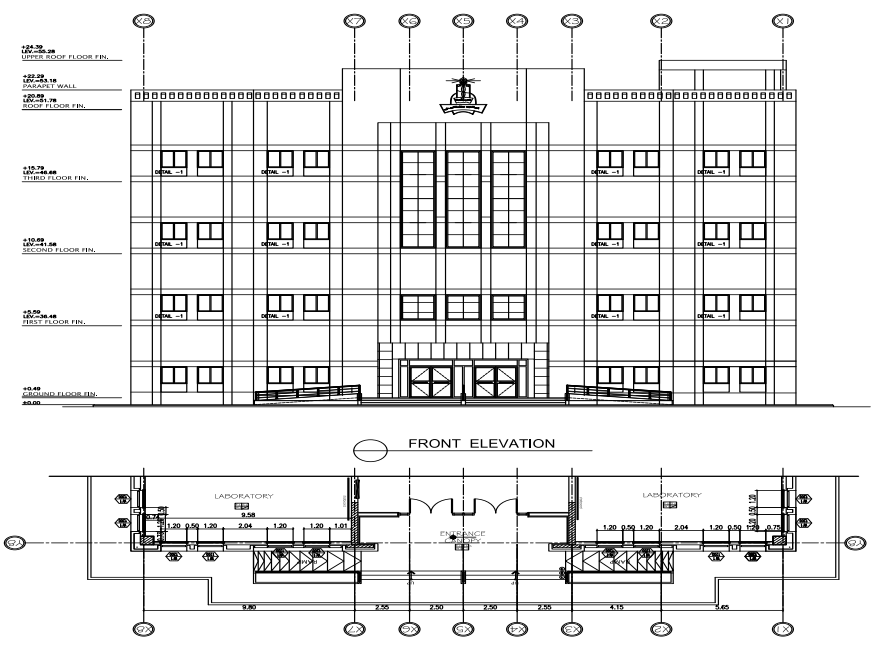

Figure 8: Front elevation of the building

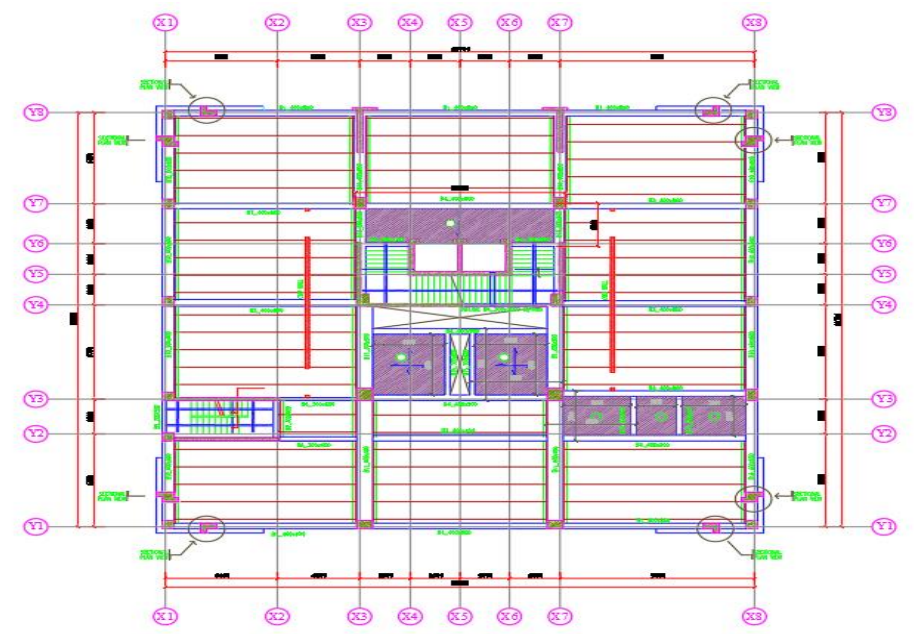

Figure 9: Shows the Ground floor plan
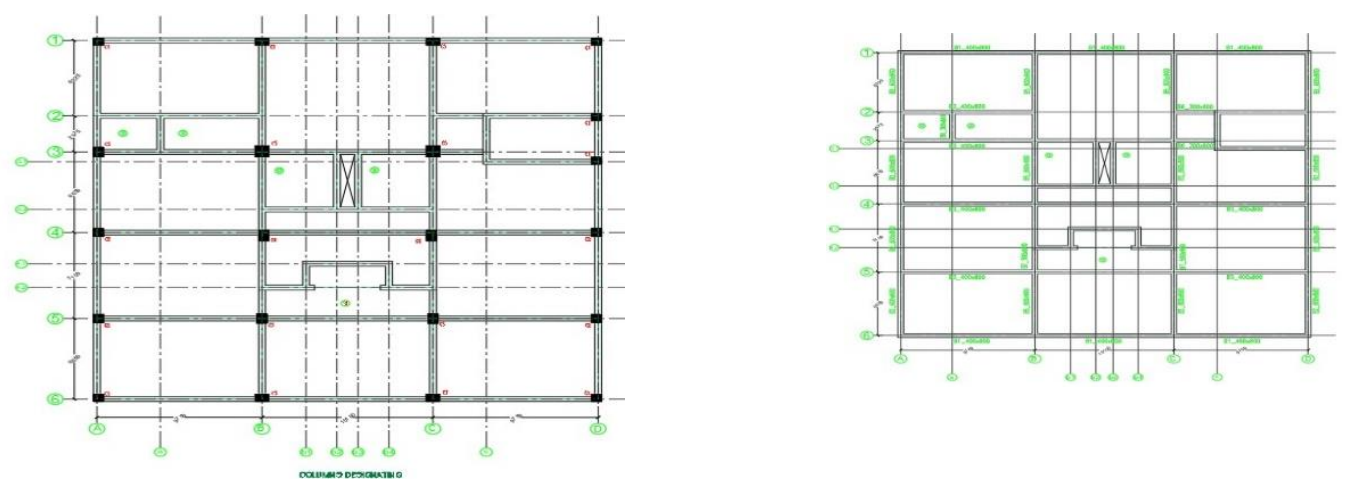

Figure 10: Shows Column and Beam Positioning

\section{Simulation Models}

It is essential to specify the codes used in the project to design and plan the process, and vital to clarify the types of load to create an appropriate analysis process. A design code is a record which set rules for the design of a new project. It can be used in the design and planning process, monitoring other forms of guidance commonly used in the English planning system over decades. 
The Codes used are American Concrete Institute (ACI 318-08) code, Saudi Building Code (SBC), International Building Code UBC-1997, and Minimum Design Loads for Buildings and Other Structures ASCE_7-10. SBC (2018),

In structural design, the presumed loads are specific international and local design codes for varieties of structures and geographic sites. In addition to the load magnitude, its distribution, frequency of occurrence and nature are vital elements of the design. The loads are the reason for deformation and stresses in structures, while the methods of structural analysis evaluate their effects.

Dynamic loads are loads that show noteworthy effects, like wind gusts, strong earthquakes, impact loads and waves. As a complication of the analysis, dynamic loads are usually considered equivalent loads for the normal design of common structures. Design codes generally indicate various load combinations and weighting factors for every load type to ensure a structure's security under various loading circumstances. The Load Combination Equations are modeled according to ACI 318. ACI (2019). The SAP2000 3D Model of a threestorey building is shown in figures 11 and 12 below. SAP2000, C. S. I. (2020).

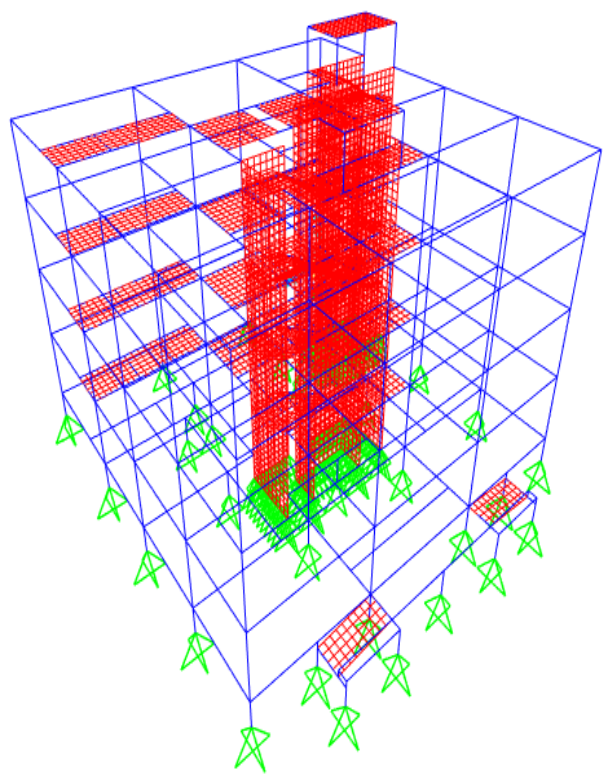

Figure 11: SAP2000 Model

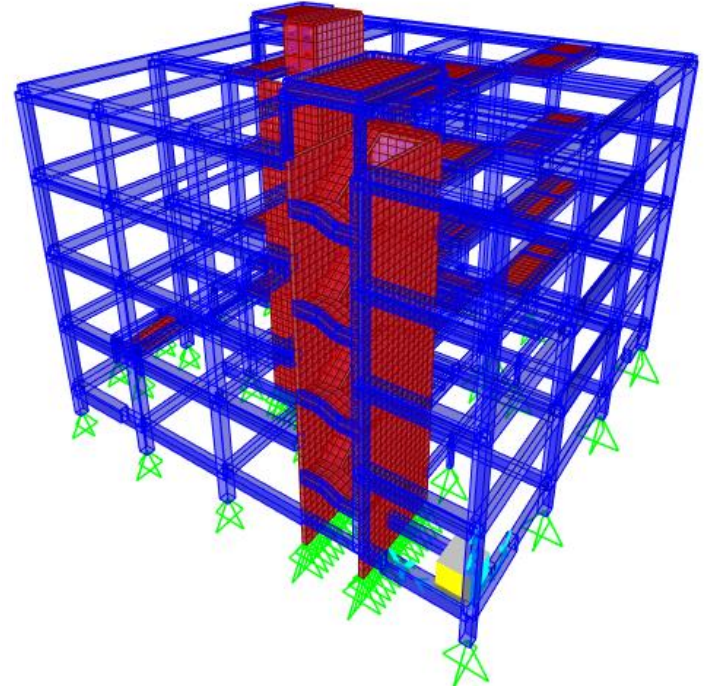

Figure 12: SAP model 3D

\section{Detailed Time History Analysis Results}

The time of oscillation of the building during the seismic interval for the frame of the structure is $t=0.648 \mathrm{~s}$, and it is known that this period must be less than this value by using fluid viscous dampers. By applying dampers to the first floor for the dampers which will have the maximum effect. It can also be seen that the time was reduced from 0.62 to 0.51 second, which is a noticeable difference. However, it is required less than that period to ensure that our structure is stable and safe. The deformed shapes in extruded views for different floors are shown in figures $13,14,15$ and 16.
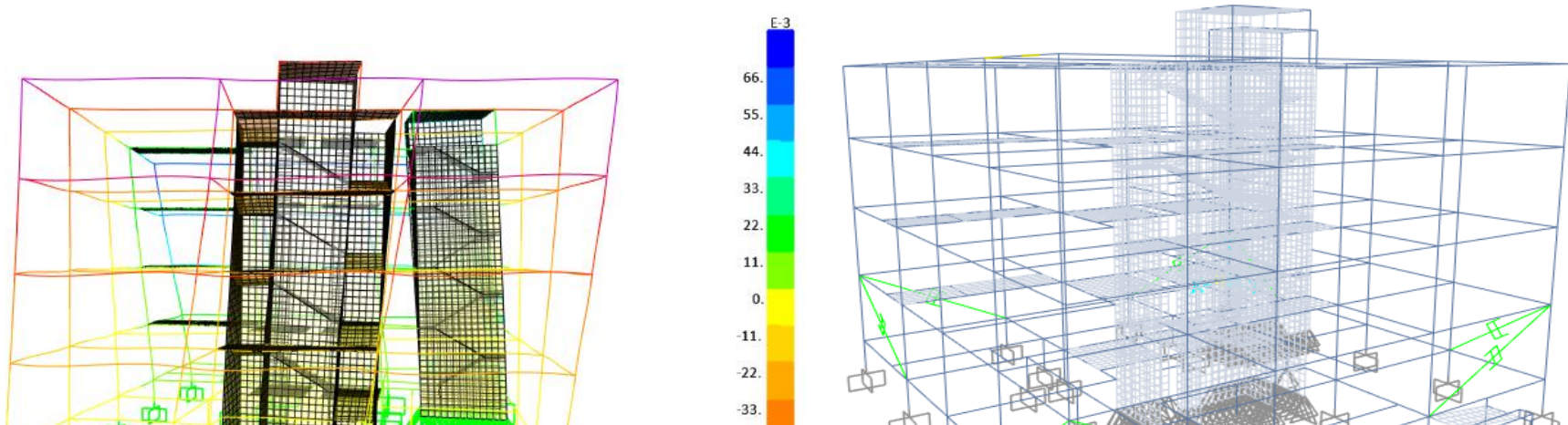
Figure 13: The deformed shape of structure frame without dampers and Structure frame with dampers applied to one floor

The picture below clarifies the methodology by which fluid viscous dampers are fixed to the structural frame for one story only, using SAP 2000. FVD has been chosen to at the corners to achieve the maximum effect of the dampers. In case of damper installed at the center, the readings were less than the readings obtained by this method. SAP2000, C. S. I. (2020).
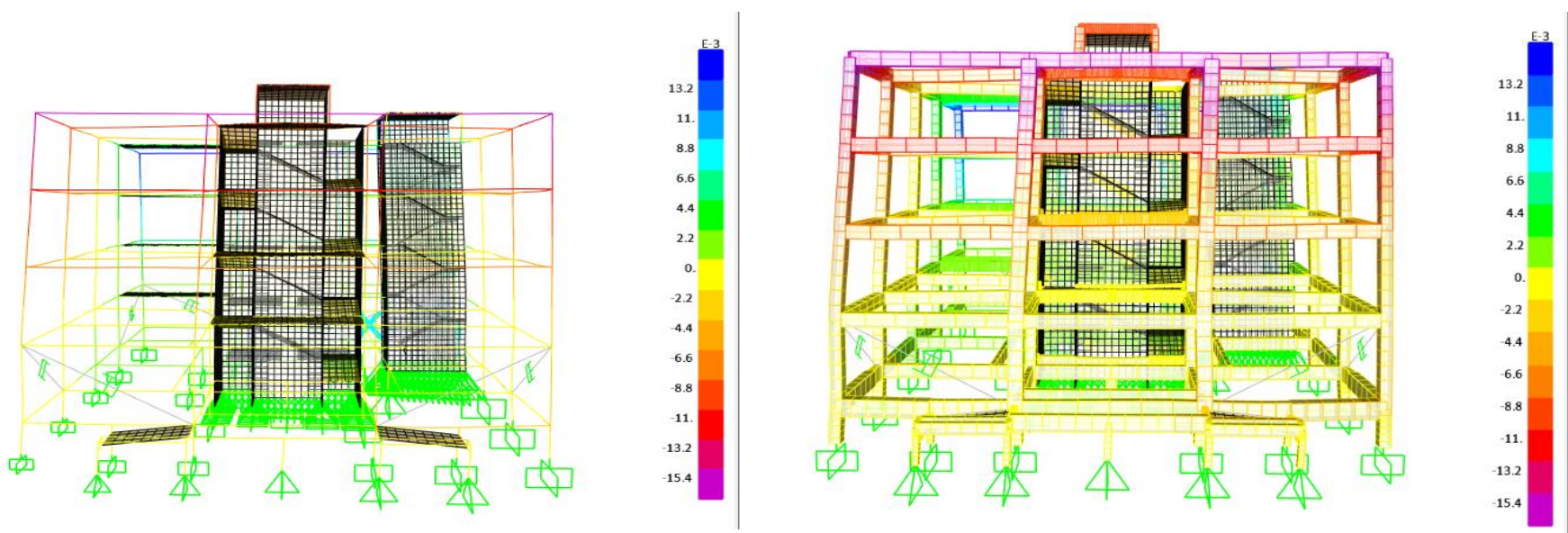

Figure 14: Deformed shape of the structure frame, dampers are applied for one floor
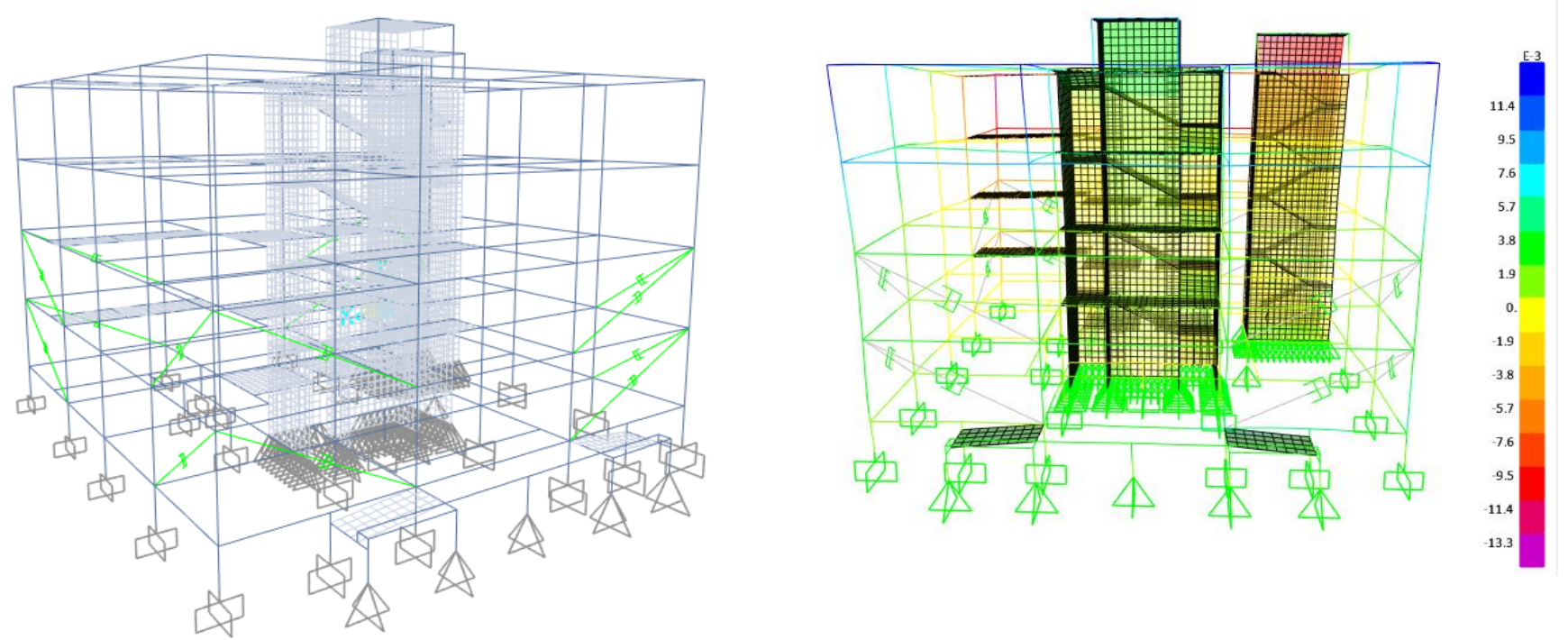

Figure15: Structure frame with dampers fixed on both first $\&$ second floor 


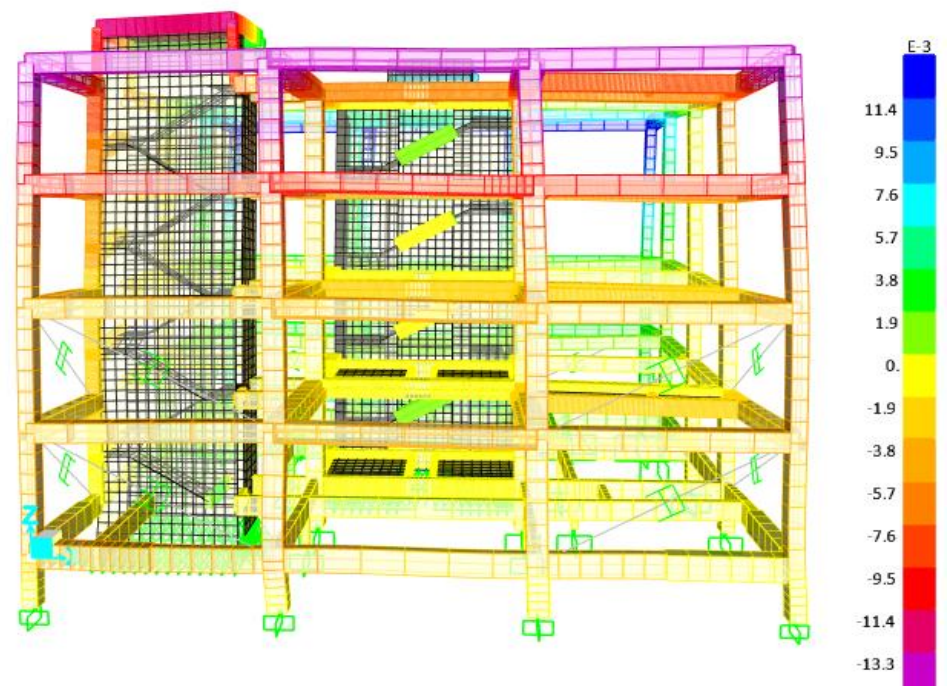

Figure 16: Extruded view, back view; dampers are applied on two floors

To conclude, the results for the time history analysis (t) in case of earthquake for different cases are shown in the table below

\begin{tabular}{|l|l|}
\hline MODEL CASE & T(s) \\
\hline Structure without applying any passive control & $0.62 \mathrm{~s}$ \\
\hline Structure with applied FVD to one floor only & $0.51 \mathrm{~s}$ \\
\hline Structure with applied FVD to first \& second floor & $0.38 \mathrm{~s}$ \\
\hline
\end{tabular}

The values shown in the table above clarify the influential role of using dampers (passive control) in reducing the oscillation time (movement time). Moreover, to continue add dampers to more stories, which would reduce the movement time of the structure even more, but that would be a waste of money and effort since the structure is already in the safe range, which is from 0.1 to 0.3 or 0.4 .

\section{Dynamic Displacement}

In Case A, one joint's dynamic displacement is displayed using SAP 2000, but no passive control (damper) is used. The picture below clarifies the dynamic movement range of joint 6683; the range for case $\mathrm{A}$ is from $-22.62 \mathrm{~mm}$ to $33.69 \mathrm{~mm}$. 
In Case B, the dynamic movement of a joint, the same joint is displayed as in the first case, using SAP 2000, but in this case a passive control (damper) is used for just one story of the structure, shown in figures 17 and 18. The picture below clarifies the dynamic movement range of joint 6683 ; the range for case $\mathrm{B}$ is from $-17.00 \mathrm{~mm}$ to $28.19 \mathrm{~mm}$ : as we can see clearly, the dynamic movement was decreased.

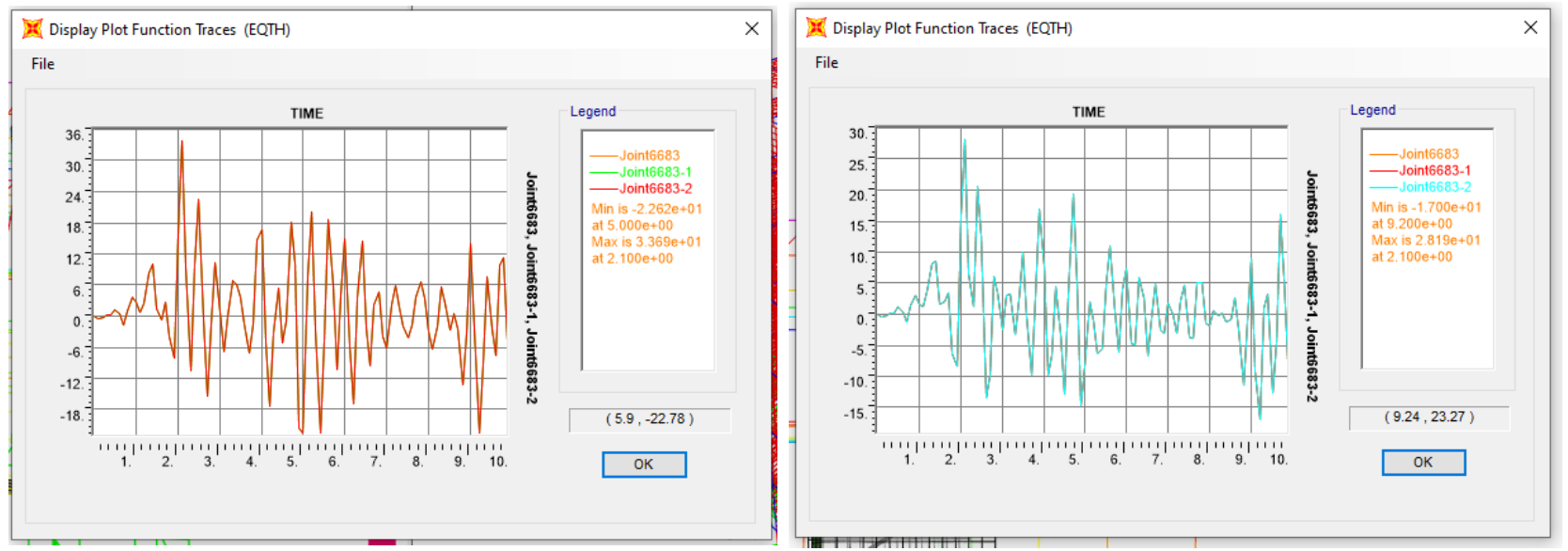

Figure 17: Illustrates the Dynamic movement range of joint 6683 is shown case $\mathrm{A}$ and case $\mathrm{B}$

In Case $\mathbf{C}$, the dynamic movement of a joint is examined; the same joint which was displayed at first, using SAP 2000, but in this case, a passive control (damper) is used for two structure stories. The picture shown below clarifies the dynamic movement range of joint 6683 ; the range for case $\mathrm{C}$ is from $-8.00 \mathrm{~mm}$ to $11.89 \mathrm{~mm}$. As we can see, the dynamic movement was decreased noticeably.

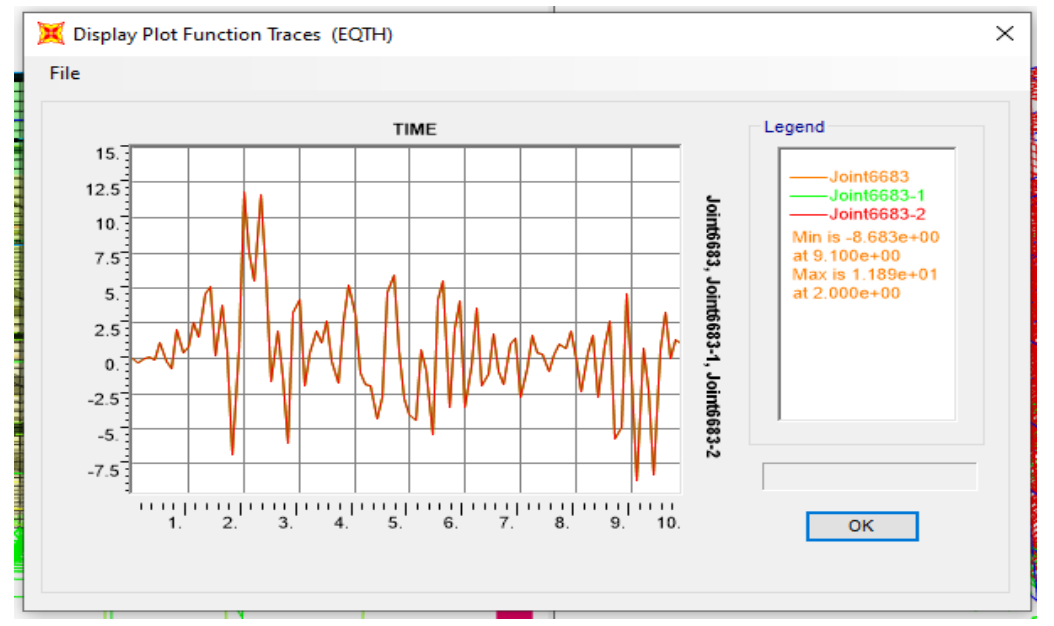

Figure18: Shows the Dynamic movement range of joint 6683 is shown, case c.

To sum up, using passive control (dampers) reduces the dynamic movement of the structure, which directly affects the structure's stability and safety conditions. Therefore, the oscillation time and dynamic movement, which are basic factors for any structure to be stable and safe, are affected directly by passive control; in our case, dampers. Keeping in mind that 
our designed structure is just three stories, we can achieve the stability and safety requirements using different concrete sections or other reinforcement conditions for our structure. However, these sections were applied and reinforcement conditions to detect the change in stability and safety conditions of the structure with and without using passive control.

\section{Static Displacement}

For these checks, two joints, 6683-1 \& 6683-2 will be tested for the same three cases which were analyzed. Case A. In this case, no passive control is used (no dampers). Case B: In this case, passive control is used; dampers are installed for one floor of the structure. Case C: In this case, passive control is used; dampers are installed for two floors of the structure.

Case A

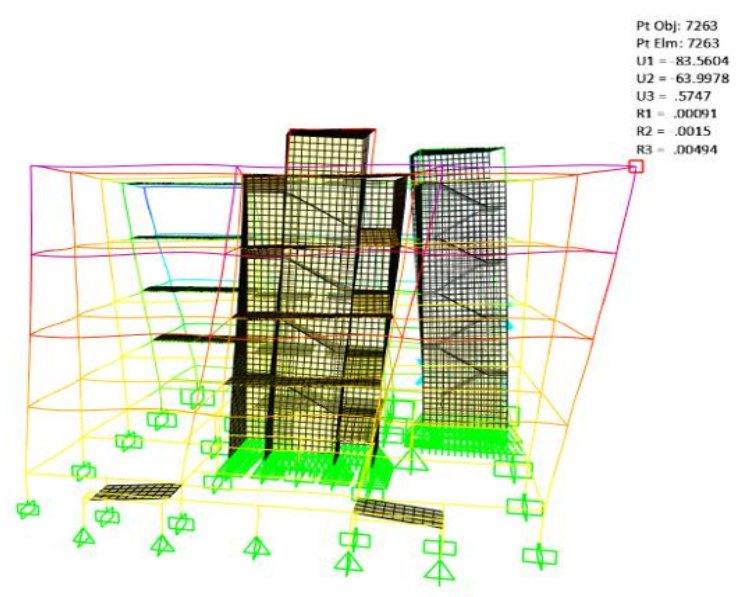

\section{Case B}

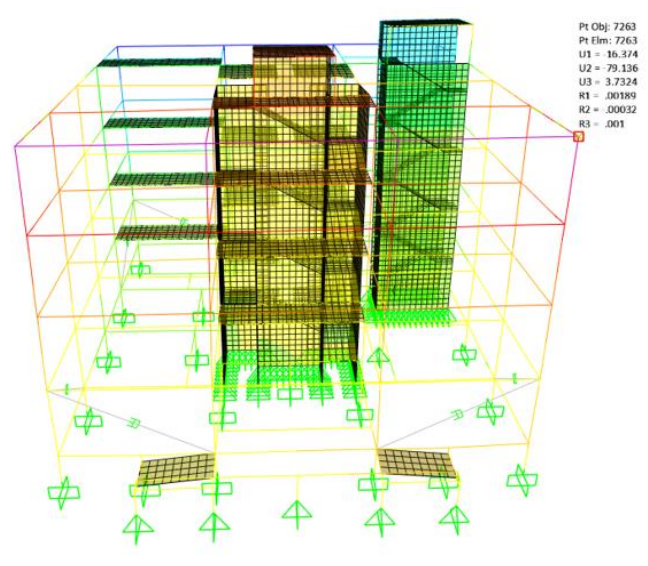

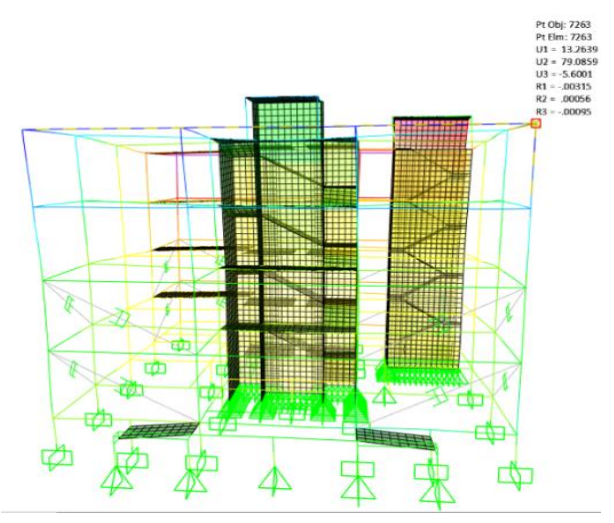

\section{Case C}

Figure 19: Static conditions for first joint case A, B and C

When checking the static movement, we consider three axes: U1, which is the movement in $\mathrm{X}$ direction; $\mathrm{U} 2$, the movement in $\mathrm{Y}$ direction; and $\mathrm{U} 3$, the movement in $\mathrm{Z}$ direction. In this picture above, in the first case, case A, where there is no passive control used to support the structure frame, the readings were for joints one and two respectively: $\mathrm{U} 1=83.56$ $\mathrm{mm}, \mathrm{U} 2=63.997 \mathrm{~mm} \& \mathrm{U} 3=0.5747 \mathrm{~mm}$; and $\mathrm{U} 1=83.56 \mathrm{~mm}, \mathrm{U} 2=82.149 \mathrm{~mm} \& \mathrm{U} 3=0.97 \mathrm{~mm}$.

Now, in case B, when the dampers were applied to one story only, the readings were for joint one and two, respectively: $\mathrm{U} 1=16.374 \mathrm{~mm}, \mathrm{U} 2=79.13 \mathrm{~mm} \& \mathrm{U} 3=3.73 \mathrm{~mm}$; and $\mathrm{U} 1=$ $16.374 \mathrm{~mm}, \mathrm{U} 2=49.40 \mathrm{~mm} \& \mathrm{U} 3=3.03 \mathrm{~mm}$. There is an obvious change in the values; most 
are less than the values in the first case, while some are slightly higher in a way that doesn't affect the stability or safety, but eventually, it is a lot better.

In case $\mathrm{C}_{2}$ when the dampers are applied to two stories, the readings were for joint one and two respectively: $\mathrm{U} 1=13.263 \mathrm{~mm}, \mathrm{U} 2=79 \mathrm{~mm} \& \mathrm{U} 3=-5.6 \mathrm{~mm}$; and $\mathrm{U} 1=13.26 \mathrm{~mm}$, $\mathrm{U} 2=50.94 \mathrm{~mm} \& \mathrm{U} 3=-5.15 \mathrm{~mm}$. The values are similar or even more reduced than case B. This means improvements in the structure frame's stability \& safety when the passive control (dampers) are fixed on the structure to achieve the maximum effect.

After the designing process, we determined the section of the following. Beams and column sections for all floors are shown in figure 8 and are as follows: Beams 1 and 3 section size $40 \mathrm{~cm}$ x $80 \mathrm{~cm}$; Beams 2 and 4 section size $60 \mathrm{~cm}$ x $80 \mathrm{~cm}$; Beam 5 section size $80 \mathrm{~cm}$ x $90 \mathrm{~cm}$; Beam 6 section size $30 \mathrm{~cm}$ x $60 \mathrm{~cm}$; Beam 7 section size $50 \mathrm{~cm}$ x $80 \mathrm{~cm}$.

Column 1 sizes $60 \mathrm{~cm}$ x $60 \mathrm{~cm}$; Column 2 sizes $60 \mathrm{~cm}$ x $70 \mathrm{~cm}$; Column 3 sizes $60 \mathrm{~cm}$ x 80 cm Column 4 sizes $60 \mathrm{~cm}$ x $90 \mathrm{~cm}$; Column 5 sizes $80 \mathrm{~cm}$ x $90 \mathrm{~cm}$.

\section{Conclusions}

In this research, the most modern models of laser scanners and accompanying software, capable of accurate capture and alignment of the point clouds, were used. The laser scans precisely captured the current geometry of each structure, which is irregular in many cases due to the inherent complex geometry, ageing, corrosion, and structural damage. A 4-story building was scanned using a 3D laser scanner to determine the architectural and structural drawings. The results concluded that the above technique provides the best outcomes for reducing seismic damage collapses. Furthermore, the outcomes can be used and helpful for future research studies related to this field.

\section{Acknowledgment and Conflict of Interest}

This research work is being financed by the Deanship of Scientific Research Islamic University of Madinah. The authors would like to thank for support. There is not any conflict of interest and ethical issues involved in this research.

\section{References}

ACI, American Concrete Institute Building Code Requirements for Structural Concrete (ACI 318 M-19) and Commentary, (2019).

Bhatti, A.Q., Wahab, A. \& Sindi, W. An overview of 3D laser scanning techniques and application on digitization of historical structures. Innov. Infrastruct. Solut. 6, 186 (2021). https://doi.org/10.1007/s41062-021-00550-9

Bhatti, A.Q. Scaled accelerographs for design of structures in Quetta, Baluchistan, Pakistan. Int J Adv Struct Eng 8, 401-410 (2016). https://doi.org/10.1007/s40091-016-0141-x 
Bhatti, A.Q., Wahab, A. Analysis and design of emergency field isolation hospital building using innovative rapidly construction prefabricated units to treat patients infected with COVID19. Innov. Infrastruct. Solut. 6, 90 (2021). https://doi.org/10.1007/s41062-020-00453-1

Bhatti, A.Q. Performance of viscoelastic dampers (VED) under various temperatures and application of magnetorheological dampers (MRD) for seismic control of structures. Mech Time-Depend Mater 17, 275-284 (2013). https://doi.org/10.1007/s11043-012-9180-2

Bhatti AQ (2016) Application of Dynamic Analysis and Modeling of Structural Concrete Insulated Panels (SCIP) for Energy Efficient Buildings in Seismic Prone Areas. J Energy Build 128:164-177 (2016) https://doi.org/10.1016/j.enbuild.2016.06.049 (ISSN: 0378-7788)

Bhatti, A.Q. Structural health monitoring of single degree of freedom flexible structure having active mass damper under seismic load. Innov. Infrastruct. Solut. 3, 33 (2018). https://doi.org/10.1007/s41062-018-0139-2

Building code - Wikipedia. 2018. Building code - Wikipedia. [ONLINE] Available at https://en.wikipedia.org/wiki/Building_code

Bhatti AQ, Hassan SZU, Rafi Z, Khatoon Z, Ali Q (2011) Probabilistic seismic hazard analysis of Islamabad, Pakistan. J Asian Earth Sci 42(3):468-478. doi:10.1016/j.jseaes.2011.05.006

\section{DAMPERS FOR SEISMIC RESISTANT STRUCTURES}

[https://theconstructor.org/earthquake/dampers-for-seismic-resistant-structures/8332/] [accessed 25/3/2019].

Ebrahim, M. A. B. (2015). 3D laser scanners' techniques overview. Int J Sci Res, 4(10), 323331.

Heysami, Alireza "Types of Dampers and their Seismic Performance during an Earthquake" Current World Environment Vol. 10 (Special Issue 1), 1002-1015, 2015.

https://www.linkedin.com/pulse/brief-idea-3d-scanning-heritage-conservation-part-1-karankamani/

ICOMOS. 2011. Guidance on Heritage Impact Assessments for Cultural World Heritage Properties. Paris, France: ICOMOS.

Mosalam, Khalid M., Shakhzod M. Takhirov, and Sangjoon Park. Applications of laser scanning to structures in laboratory tests and field surveys. Structural Control and Health Monitoring 21, no. 1 (2014): 115--134.

SAP2000, C. S. I. (2020) Analysis reference manual. Computers and Structures Inc, Berkley, California, USA

SBC, Saudi Building Code National Committee: Saudi Building Code; Concrete Structures Requirements SBC 304. 2nd edition, Saudi Arabia, (2018)

Shan DS, and Bhatti AQ, Temperature effect analysis of viscoelastic damper and magnetorheological damper for vibration control of stayed-cable, Bridge Maintenance, Safety, Management and Life Extension. May 2014, 2167, -217

Seismic Control Devices. 2019. Seismic Control Devices. [ONLINE] Available at: http://www.buildingresearch.com.np/services/erd/erd7.php.

Saudi Commission for Tourism and National Heritage, Historic Jeddah, the Gate of Makkah, State of Conservation Report, Nov 2017, 
Varum H, Teixeira-Dias F, Marques P, Pinto A and Bhatti AQ. Performance evaluation of retrofitting strategies for non-seismically designed RC buildings using steel braces, Bulletin of Earthquake Engineering, Volume 11, Issue 4 August 2013, pp. 1129-1156, 1570-761X

Wahab A., M.M.A. Aziz, A.R.M. Sam, K.Y. You, Application of microwave waveguide techniques for INVESTIGATING the effect of concrete dielectric and reflection properties during curing, Journal of Building Engineering (2021) 102209.

Wahab, A., Aziz, M. M. A., Sam, A. R. M., You, K. Y., Bhatti, A. Q., \& Kassim, K. A. (2019). Review on microwave nondestructive testing techniques and its applications in concrete technology. Construction and Building Materials, 209, 135-146.

* https://recap.autodesk.com/

** https://www.faro.com/products/construction-bim-cim/faro-scene/. 